\title{
ANALYSIS OF METROLOGICAL PROPERTIES FIBER BRAGG GRATINGS WITH A CONSTANT AND VARIABLE PERIOD
}

\author{
Tomasz Zieliński, Piotr Kisała
}

Lublin University of Technology, Institute of Electronics and Information Technology

Abstract. The paper presents periodic structures in terms of metrological properties in the distinction for a fiber Bragg grating (FBG) with a constant and changeable period. The process of their formation and characteristics as well as applications in many areas have been described. On the basis of the literature, the results of research and measurements of measurable quantities such as temperature and stress made by periodic structures applied to the fiber of the optical fiber are presented. Analysis of the presented measurements allowed to mark the ranges and accuracy of measurements of individual applications.

Slowa kluczowe: fiber Bragg grating, optical sensors, uniform fiber Bragg grating, chirped fiber Bragg grating

\section{ANALIZA WLAŚCIWOŚCI METROLOGICZNYCH SIATEK BRAGGA ZE STALYM I ZMIENNYM OKRESEM}

\begin{abstract}
W pracy przedstawiono struktury periodyczne pod kątem własności metrologicznych w rozróżnieniu na światłowodowe siatki Bragga (FBG - ang.: Fiber Bragg Grating) o statym i zmiennym okresie. Opisano proces ich powstawania oraz cechy charakterystyczne jak $i$ zastosowania $w$ wielu dziedzinach. W oparciu o literaturę zaprezentowano wyniki badań $i$ pomiarów takich wielkości mierzalnych jak temperatura $i$ naprężenie dokonywanych strukturami periodycznymi naniesionymi na włókno światlowodu. Analiza zaprezentowanych pomiarów pozwoliła nakreślić zakresy oraz dokładności pomiarów poszczególnych aplikacji.
\end{abstract}

Keywords: światłowodowa siatka Bragga, czujnik optyczny, jednorodna światłowodowa siatka Bragga, chirpowa światłowodowa siatka Bragga

\section{Introduction}

The phenomenon of photosensitivity in optical fiber is the main phenomenon involving the fabrication of Bragg gratings in the fiber core, which for the first time showed K.O. Hill et al. In 1978 [14]. However, only eleven years later (1989), published by G.Meltz and colleagues [39], a pioneering work in the production of Bragg grids, has become a milestone for fiber optic sensors. It describes a method for producing bragga nets using two intersecting UV rays, directed to the side of an optical fiber falling on its cladding. This method enabled the creation of a mesh with a fixed period and depth of modulation, while being much more efficient in comparison to previous methods that did not give such possibilities to change the parameters of the mesh [16].

The information that contains the aforementioned publications initiated the dynamic development of optical fiber technology around the world. In a short time, many new methods for the production of Bragg grids arose, and as a result, their quality and the number of potential applications drastically increased.

The replacement of the first methods of producing periodic structures such as internal writing [14] and holographic technique [39], phase mask technique $[2,15]$ allowed for a significant reduction in manufacturing costs through the use of cheaper devices in the production process while increasing product quality. The disadvantage of the phase mask technique is the need to use a separate mask for each other Bragg wavelength. However, it is possible to tune the wavelengths by tensioning the fibers during the photocoding process; the Bragg wavelength of the loosened fiber will vary by $2 \mathrm{~nm}$ [16].

The phase mask technique ensures not only high-quality periodic structures, but is very flexible, it can be used to produce meshes with controlled spectral characteristics. For example, the typical spectral response of a uniform Gragge (uniform grating), one that has a constant period of refractive index and a constant depth of modulation along the length of the fiber, has side bands/secondary maxima on both sides of the main reflection peak. In applications such as wavelength division multiplexing, this type of response is not desirable [16]. Along with the use of the phase mask technique, it is possible to silence the sidebands with the apodization procedure, the change in modulation depth $[1,37]$.

The phase mask technique has also been adapted to produce periodic structures with variable periods, those that have a variable period of refractive index along the length of the mesh to extend their spectral response.
Another method that enabled the development of fiber optic sensors is the point-by-point $(\mathrm{PbP})$ method. Despite the first presentation of the structure made in this $\mathrm{PbP}$ method in 1993 [36], it did not arouse much interest until the use of light sources with femtosecond pulse lengths [46]. This technique allows the recording of Bragg grids in photonic fibers [28]. The advantage of this technique is also the possibility of using the produced periodic structures at temperatures close to $1000^{\circ} \mathrm{C}$ due to structural modifications of the glass during their production [38].

The use of fiber-optic periodic structures as a sensor is very popular due to the possibility of using them in flammable and chemically aggressive environments, their great advantage is that they are insensitive to changes in the electromagnetic field. Negligible weight and size make it possible in most cases to omit their influence on the object under study [26].

Thanks to continuous research on the use of fiber optic Bragg grids as measuring sensors, many methods have been developed for their application. Most of the methods presented in the published works are based on the multiple use of FBG sensors in a single application.

Simple batch structures such as homogeneous Bragg gratings, thanks to the properties of linear processing of magnitude measured on the Bragg wave shift, are great transducers of physical quantities such as temperature and stress [24, 35], displacement [48] or force [10]. These structures are also widely used in the study of many physical quantities simultaneously, eg: elongation and temperature [25], or strength and temperature [22].

Homogeneous optical fiber optical sensors are also tested for their application in the measurement of stress values occurring in the structures of aircraft wings, masts of sea-going ships, or examination of the condition of bridge structures - constructions particularly exposed to the influence of external forces. Noteworthy is the use of this structure in the field of medicine. The optical sensor allows you to monitor the vibrations of the body caused by basic life activities, such as the rhythm of the heartbeat and breathing. This use of periodic structure gives a lot of possibilities in the field of monitoring the physiological state of the examined person without the need of direct contact with the skin of the patient (gel or dry electrodes) [7].

In addition to the use of homogeneous Bragg grids as sensors, tests are also carried out in the field of their use as optical switches based on optical bistability. The first works describing the optical bistability phenomena using the Bragg's single lattice appeared in 1995. They present the optical switching threshold, which 
occurred for the input optical grid signal of $200 \mathrm{~W}$, which is a much higher value than the optical switching power level [43].

An article from 2015 proposes an optical bistable system that uses two homogeneous Bragg grids and an erbium doped optical fiber. It has been shown that the level of switching power of the system can be reduced to $12.5 \mathrm{~mW}$ by increasing the length of the erbium fiber characterized by a high value of the non-linear refractive index, and it was noted that the change in the length of the grid from $5 \mathrm{~mm}$ to $4 \mathrm{~mm}$ causes almost double increase in switching power [21].

Bragg grids with a variable period have many applications. Particularly linear periodic structures of this type have found a special place in optics: as devices for correcting dispersion and compensation. This application has also resulted in the production of very long, high-quality wide-band meshes, intended for highspeed transmission over long distances [27, 33], and in WDM transmission $[8,11,40]$. Some of the other applications include high order fiber dispersion compensation, ASE attenuation, amplifier gain flattening, bandpass filters [20] and Fourier transform in real time [3].

A very interesting application of CFBG is its use in an application to replace an optical spectrum analyzer. In the article from 2017. presents a CFBG interrogation system that can simultaneously measure positive/negative deformations and temperature changes, with a resolution of about $1 \mu \varepsilon$ (thanks to a photodiode with a sensitivity of $0.3-0.4 \mathrm{nW}$ ). A chirp of $5 \mathrm{~nm}$ can provide a strain measurement range of around $\pm 4000 \mu \varepsilon$ [34].

Bragg's chirp grids have also found their application as measuring courts used to measure impact velocity, detonation velocity, shock wave profile or pressure profile in inert and energetic materials. The diameter of the measuring judge using the chirp structure does not exceed $150 \mu \mathrm{m}$, which allows it to be placed directly in the material without interfering with physical phenomena. The sensor placed in this way enables the shockwaves to be traced inside the material using the Bragg wavelength. In this application, the speed (several $\mathrm{km} / \mathrm{s}$ ) and measurements of the shockwave profile are carried out by recording the reflected spectrum from the CFBG [4].

Common application of the sensor using the Bragg mesh with a constant and variable period is presented in the publication from 2012. The author presented a method enabling the simultaneous measurement of deformation and temperature using a single, uniform Bragg mesh with a properly selected chirp zone. Providing the same sensitivity to temperature and different sensitivity to deformation of two parts of the sensor and experimental measurements of the quality of the proposed system made it possible to state that the presented application is fully functional. The sensor grid was placed in such a way that its half was in the zone of variable axial stresses induced by changes in the cross-section of the sample, while the other half was in the zone with a constant cross-section of the sample and constant strain value. In this work, the author also presented the obtained nonlinear errors in the processing characteristics for measuring the deformation and temperature of the proposed system, amounting to $2.7 \%$ and $1.5 \%$ respectively, with the sensitivity factors for strain and temperature being respectively $0.77 \times 10^{-6} \mathrm{~m} / \varepsilon$ and $4.13 \times 10^{-12} \mathrm{~m} / \mathrm{K}$. The maximum differences shown between the values obtained from the intermediate measurement and the set values were $110 \mu \varepsilon$ for the deformation and $3.8^{\circ} \mathrm{C}$ for the temperature, while for the deformation $2,500 \mu \varepsilon$ and the temperature $40^{\circ} \mathrm{C}$ [23].

While discussing the subject of Bragg grids with a constant and variable period, it is worth mentioning the possibility of transforming homogeneous FBG into chirp using, for example, strain gradient or temperature along the length of a homogeneous FBG. The deformation or temperature gradient can be produced by various methods:

- combining FBG with the base using a soft adhesive, which gradually relieves the stress of the mesh [12],

- narrowing of the external FBG diameter using acid [42],

- using a cantilevered beam with non-uniform cross-section [13],
- deposition of different thicknesses of the retaining film on the FBG surface with a constant period [9].

The paper presents issues concerning optical parameters of homogeneous periodic structures and variable-period structures, and their use as transducers for temperature and stress measurement.

\section{Optical parameters of periodic structures with a uniform and variable period}

The Bragg fiber optic mesh is referred to as glass regions with different refractive index values stored in the single-mode optical fiber core.

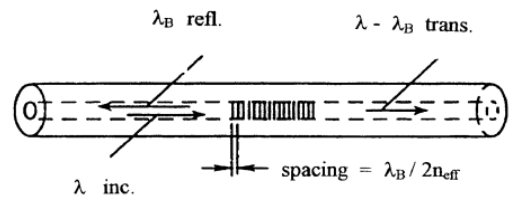

Fig. 1. Schematic of optical fiber with the Bragg mesh applied [20]

These periodic changes have a sinusoidal character, which characterizes their period $\Lambda$, and their amplitude $\Delta \mathrm{n}$. Propagation of a beam of light in a fiber with a direction perpendicular to the Bragg grating causes the reflection of a specific wavelength from the beam incident on it. The structure in question is capable of backward reflection of the wavelength satisfying the Bragg condition [20]:

$$
\mathrm{m} \lambda_{\boldsymbol{B}}=2 \cdot n_{e f f} \bullet \Lambda
$$

where: $\mathrm{m}$ - natural number defining the order of reflection of radiation, $\lambda_{\boldsymbol{B}}-$ Bragg wave length, $n_{e f f}-$ the average value of the modulation component of the refractive index modulation in the Bragg structure, $\Lambda$ - Bragg grid.

Reflected rays add in the phase creating a ray obliterated from the Bragg structure on the principle of constructive interference, while the remaining part of radiation, which does not meet the condition (1) is subject to further lossless propagation [20].

Considering the fixed network and the distribution of the refractive index inside the periodic structure, we are able to list different types of Bragg grids. In the further part of the work, two types of fiber-optic Bragg nets will be discussed, homogeneous and chirpova in terms of metrology.

The homogeneous Bragg mesh is the basic type of this type of structures. It is characterized by a constant value of modulation depth and a constant period of refraction along the fiber axis, as shown in Fig. 2.

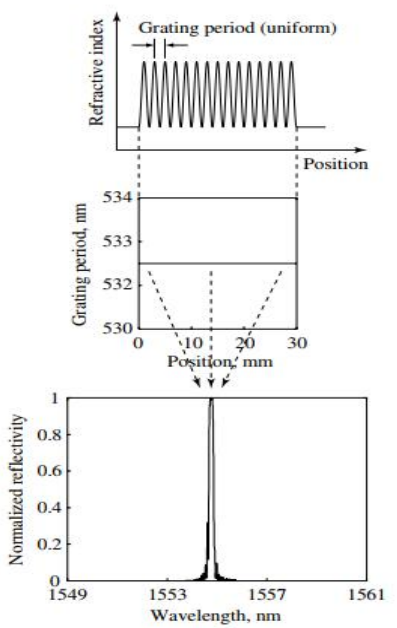

Fig. 2. Diagram of a single FBG with its corresponding spectrum [20]

A structure that has a heterogeneous value of the period along its length has been called Chirp. Chirp can take many different forms, it can differ symmetrically, growing or decreasing in the 
period. Chirp may be linear, square or may have spikes over a period of time. The grid may also have a period that changes randomly along its length. In Figure 3. the diagram of the Bragg's chirp grid and its corresponding spectrum are shown.

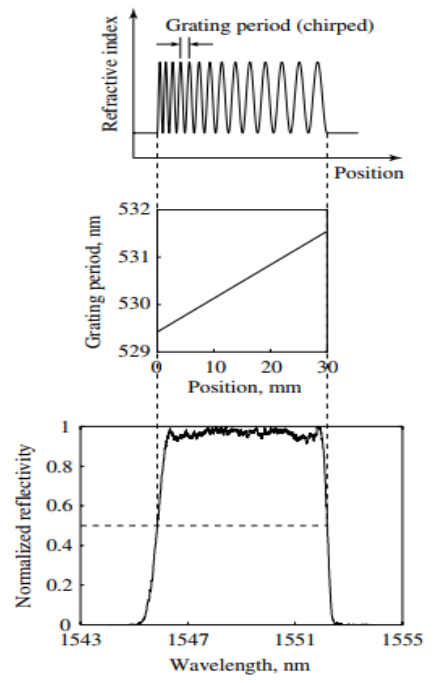

Fig. 3. Chirp FBG diagram with the corresponding spectrum [20]

Proper analysis of metrological properties should be based on qualitative indicators of optical fiber periodic structures. The assessment is made by analyzing the spectral spectra obtained in the result of the tests, these may be transmission or reflection spectra.

One of the qualitative indicators is the reflectance of the periodic structure. In Figure 4, the reflectance value $\mathrm{R}$ is indicated, which is the ratio of the difference in power values for the part of the characteristic out of the transmission peak, which is the reference power and the minimum power value at the summit point of the transmission peak to the reference power value. Spectral changes in the power level of the spectrum in the real measurement of the spectral characteristics result from the light source used to measure. The method to minimize the impact of the shape of the spectral characteristic of the source is to use the quotient of two measured spectra, the optical fiber spectrum without the recorded periodic structure and the spectral characteristics of the Bragg structure [20].

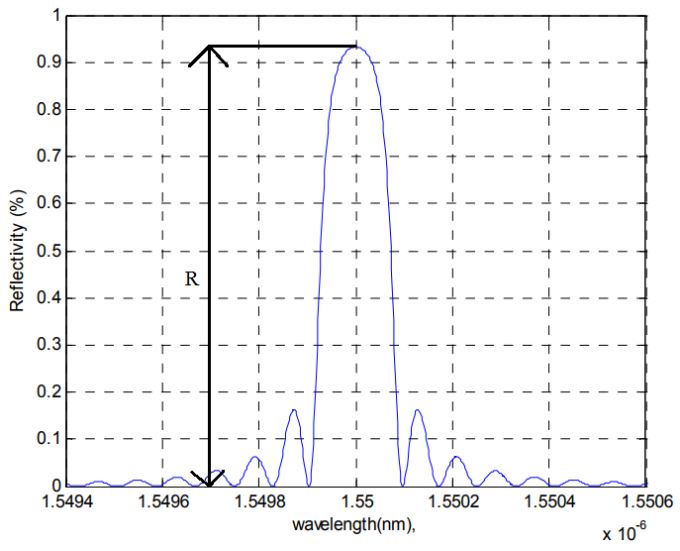

Fig. 4. Determination of FBG reflectance based on its reflection characteristics

The actual spectral characteristics of the Bragg structures differ from the ideal characteristics. Deformation consists in the occurrence of sidebands on both sides of the reflective peak and the slope of the slope of the same reflective peak of the net as shown in Fig. 5.

The RL sideband reflexivity is an important qualitative indicator affecting the applicability and accuracy of the Bragg structure used. It was defined as the ratio of the amplitude of the reflection of the radiation of the first-order ribbon and the main peak.
Obtaining minimal reflectance of the first-order lateral webs (with the highest amplitude) in the Bragg structure manufacturing process indicates high quality of the obtained structure.

The reason for the formation of side bands that are part of the spectrum are the extreme areas of the Bragg structure with a steep slope of the refractive index. The method for leveling the sidebands is to change the shape of the refractive index profile along the optical fiber axis (apodization) during the Bragg structure fabrication process.

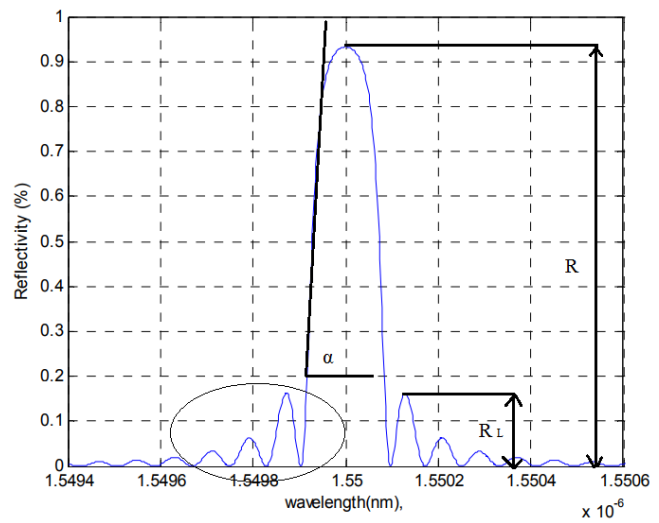

Fig. 5. The spectral characteristics of the Braga structure with marked slope line and sidebands and determination of their reflectance

The research results presented in the literature prove that for a Bragg structure with a length of $\mathrm{L}=5 \mathrm{~mm}$, the maximum reflectance is about $60 \%$, while for a structure with a length of $\mathrm{L}=25 \mathrm{~mm}$, the maximum reflectance is already $99.98 \%$. However, increasing the length of the grid, despite obtaining high reflectance, causes a drastic increase in the refinement of the sidebands [17]. After applying apodization of the Bragg structures, the mesh with a length of $\mathrm{L}=10 \mathrm{~mm}$ obtained a reflectance of about $60 \%$, while a reflectance of $99.99 \%$ was indicated with a Bragg structure equal to $\mathrm{L}=45 \mathrm{~mm}$. Despite the necessity to increase the length of Bragg structures after apodization in order to achieve the highest possible reflectance, nearly ideal spectra were obtained that were not burdened with side bands [17]

Half width FWHM (Full Width at Half Maximum), is a qualitative indicator defining the spectral width of the reflection of the periodic structure.

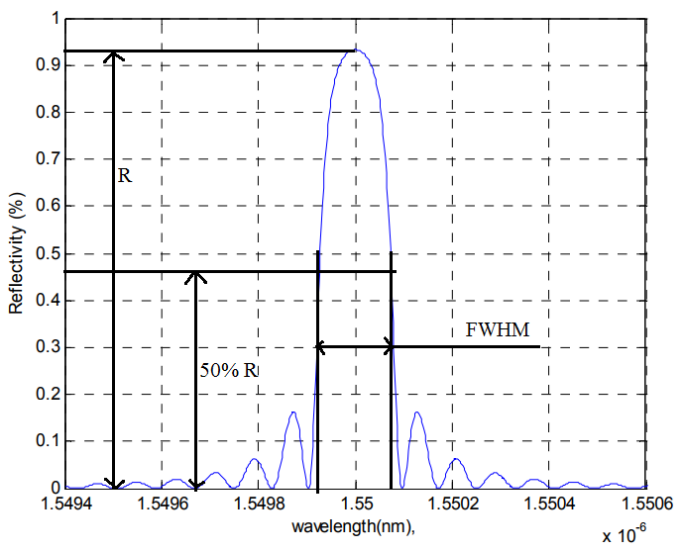

Fig. 6. Reflection spectrum with marked half width FWHM

Figure 6 shows the reflection spectrum with the half-width FWHM indicated, which is defined as the spectral distance between two points of the main peak of the reflection grid, at which the course takes half of peak values [20].

The studies presented in the literature define a range of typical FWHM half-width values, starting at $10 \mathrm{pm}$ for Bragg structures with a constant period [6], and ending with CFBG grids, reaching

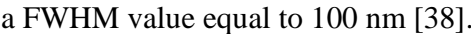


Half-width measured in fixed-term structures is a very important parameter considering the use of the Bragg fiber optic mesh in sensor applications. The narrowing of the FWHM width makes it possible to increase the detection range leading to the measurement of very small deformations. As an example, it is worth citing a special type of mesh, $\pi \mathrm{FBG}$, whose spectrum reflects the discontinuity caused by the $\pi$-phase cut in the central part of the mesh. Thanks to the application of $\pi \mathrm{FBG}$ in the sensor application, a half width equal to FWHM $=10 \mathrm{pm}$ can be achieved, and the use of the $\pi$ phase shift area allows to reduce the effective length of the sensor, making it particularly suitable for detecting high frequency ultrasound [6].

Each of the qualitative parameters described above marked in Fig. 4, Fig. 5, Fig. 6, presented as reflection spectra for a Bragg structure with a fixed period, can be directly related to a structure with a variable period as shown in Fig. 7 .

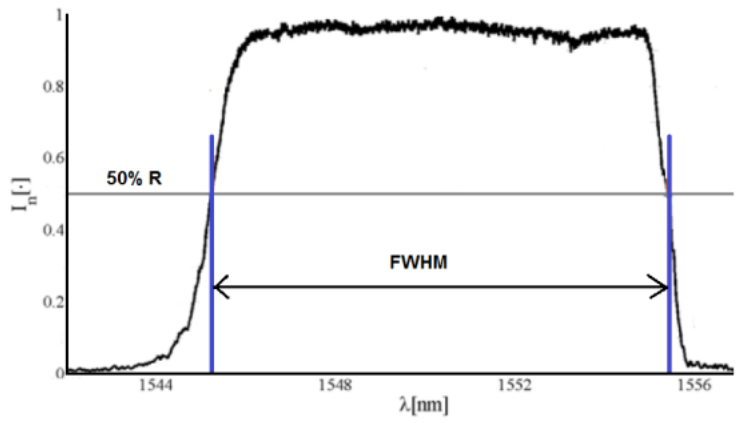

Fig. 7. Reflectance spectrum of CFBG structure with marked half width FWHM, side bands and reflectance

\section{Uniform and chirp grids as transducers for temperature and stress measurement}

Analyzing the research presented in the publications, we can observe a great interest in sensors based on Bragg fiber optic nets. Among the many applications, FBG sensors are particularly useful for measuring stresses or temperatures, since both stress and temperature information are encoded in the optical fiber as a wavelength shift.

An important parameter conditioning the use of the Bragg structure as a measuring transducer is a typical measuring range. In this part of the article a typical measuring range will be described for the temperature measured with different types of Braaga structure.

Uniform Optic Bragg type I fiber mesh, characterized by a monotonic increase in the depth of the refractive index modulation as a function of the amount of energy delivered to the fiber in the recording process. They are usually used at temperatures up to $300^{\circ} \mathrm{C}$ because of their strength [30].

Bragg type II grids are created by increasing the energy of radiation during the recording process which can lead to physical damage in the fiber core or at the edge of the shell and core. A characteristic feature of this type of mesh is high temperature resistance, exceeding $800^{\circ} \mathrm{C}$, and in some cases reaching $1200^{\circ} \mathrm{C}$. This high temperature resistance was achieved due to the fabrication of the structures under investigation with the use of laser pulses of femtosecond lengths $[39,40]$. In 2002, for the first time, the type IA structure was described, which is characterized by a higher temperature resistance compared to type I mesh, reaching the limit of $500^{\circ} \mathrm{C}[5,32]$.

Another group of FBG structures are type IIA grids. Their temperature resistance fluctuates within $500^{\circ} \mathrm{C}$, yet they are characterized by the highest temperature sensitivity from all types of meshes, taking into account stresses [19, 41].

Analyzing publications published in recent years, we can notice other types of Bragg's products. Table 1. shows all types of fiber optic Bragg grids with respect to the maximum temperature at which they can be used.

The fact that data relating to temperature and stress is signaled by the shift of the wavelength in a fiber optic cable forces the execution of a system that allows measuring the stress of the examined element, distinguishing the influence of the ambient temperature and the tested element. The Bragg wavelength of the FBG sensor depends mainly on the deformation, but varies with the change in temperature. At a temperature change of $1{ }^{\circ} \mathrm{C}$, the measured stress usually has an error of $11 \mu \varepsilon$ [45].

Tab. 1. Types of fiber optic Bragg grids [5]

\begin{tabular}{|c|c|}
\hline Grids type & Thermal durability \\
\hline Type I & $\sim 320^{\circ} \mathrm{C}$ \\
\hline Type IIA; (Type In) & $800^{\circ} \mathrm{C}$ \\
\hline Type I $\left(H_{2}\right) ;($ Type IH) & $<320^{\circ} \mathrm{C}$ \\
\hline Type IA; $($ Type IHp) & $500^{\circ} \mathrm{C}$ \\
\hline Type IHs & $600^{\circ} \mathrm{C}$ \\
\hline Type II & $>1000^{\circ} \mathrm{C}$ \\
\hline Type R & $>1000^{\circ} \mathrm{C}$ \\
\hline
\end{tabular}

To achieve higher accuracy, FBG sensors require temperature compensation. Many methods have been developed to measure stresses with temperature compensation. One of the first methods published in 1995 is the use of a stretched net in a packet containing two materials with different coefficients of thermal expansion. As the temperature rises, stress gradually releases, compensating for the temperature dependence on the Bragg wavelength. The Bragg fiber optic mesh mounted in the above-mentioned package, $50 \mathrm{~mm}$ long and $5 \mathrm{~mm}$ in diameter, showed a total variation of Bragg wavelength $0.07 \mathrm{~nm}$ in the temperature range of $100^{\circ} \mathrm{C}$, compared with $0.92 \mathrm{~nm}$ for uncompensated mesh as shown in Figure 8 [18].

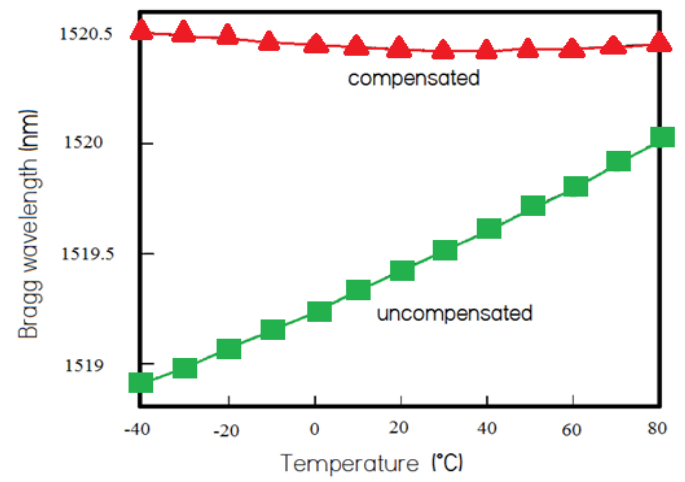

Fig. 8. Bragg wavelength graph with respect to the temperature with marked values for Bragg mesh without compensation and temperature compensation [47]

The high interest in fiber-optic temperature and stress sensors translates into published works in which we can distinguish many methods and applications of these periodic structures. The results of publications that outline the accuracy and measurement ranges of given structures will be presented below.

One of the first publications is the article from 1996. describing the technique of simultaneous, independent temperature and deformation measurement using the Bagga fiber optic sensors. Two structures with closely spaced mid-wavelengths are recorded on both sides of the weave between two fibers of different diameters (Corning PMF-38 - $80 \mu \mathrm{m}$ and Snectran FS SMC-A0780B $125 \mu \mathrm{m})$. Batch structures exhibit similar temperature sensitivity but different strain reactions to applied stresses. The maximum error is $\pm 17 \mu \varepsilon$ and $\pm 1{ }^{\circ} \mathrm{C}$ for a measuring range of $2,500 \mu \varepsilon$ and $120^{\circ} \mathrm{C}$. The test results are presented in the form of graphs Fig. 9 and Fig. 10 [18]. 


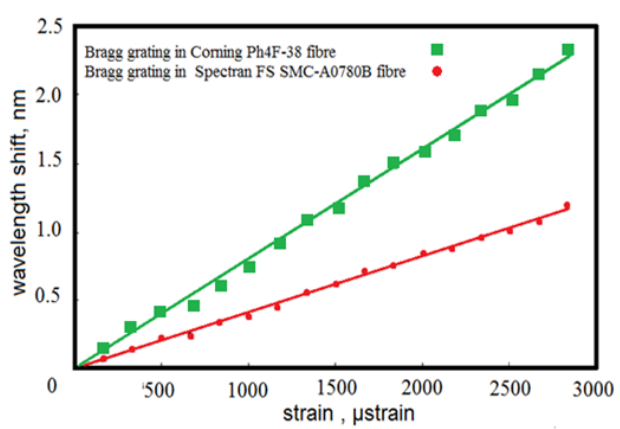

Fig. 9. Graph showing the stress response of a pair of periodic structures [18]

Analyzing the above graphs, we can notice that the stress response of both periodic structures differs to a large extent from each other. The gradient of the stress graph shown is $0.42 \pm 5 \times 10^{-3} \mathrm{pm} / \mu$ strain for the Bragg mesh made on Corning fiber and $0.81 \pm 7.8 \times 10^{-3} \mathrm{pm} / \mu$ strain for the Bragg mesh made on the Spectran fiber [18]

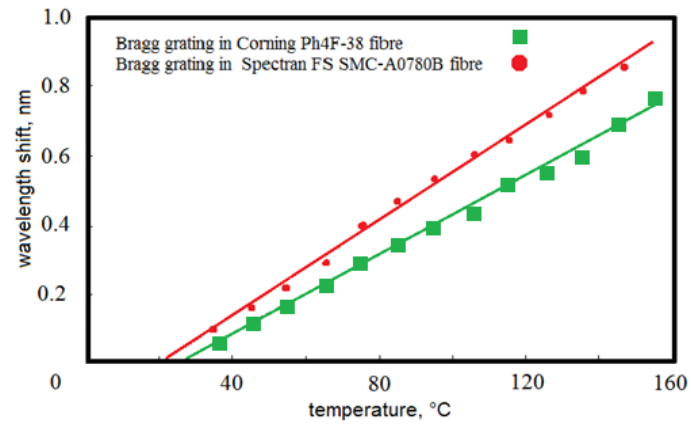

Fig. 10. Graph showing the temperature response of a pair of periodic structures [18]

In the case of a graph showing the temperature response, we can observe that the responses of individual periodic structures are very similar to each other. The gradient of the temperature response graph is $7.0 \pm 0.1 \mu \mathrm{m} /{ }^{\circ} \mathrm{C}$ of the Brgg mesh made on the Corning fiber and $5.7 \pm 0.1 \mathrm{pm} /{ }^{\circ} \mathrm{C}$ for the Brgg mesh made on the Spectran fiber [18].

The temperature and stress can also be measured with one Bragg fiber optic mesh. The publication from 2010 presents a method of simultaneous measurement of both these quantities using a single periodic structure made on a tapered fiber. The implementation of a homogeneous periodic structure on a tapered optical fiber allows to obtain a heterogeneous (chirp) structure after undergoing stress. The existence of stress-induced chirp allowed the authors to collect information encoded not only in Bragg's wavelength but also in the FWHM grid. An important feature of the periodic structure, related to the insensitivity of FWHM to temperature changes, allowed to measure temperature and strain with uncertainty of $\pm 1.9^{\circ} \mathrm{C}$ and $15.3 \mu \varepsilon$ respectively. The measurement was carried out at a constant stress of $1500 \mu \varepsilon$ and a temperature change in the range from 20 to $65^{\circ} \mathrm{C}$, and at a constant temperature of $40^{\circ} \mathrm{C}$ and variable tension [31]

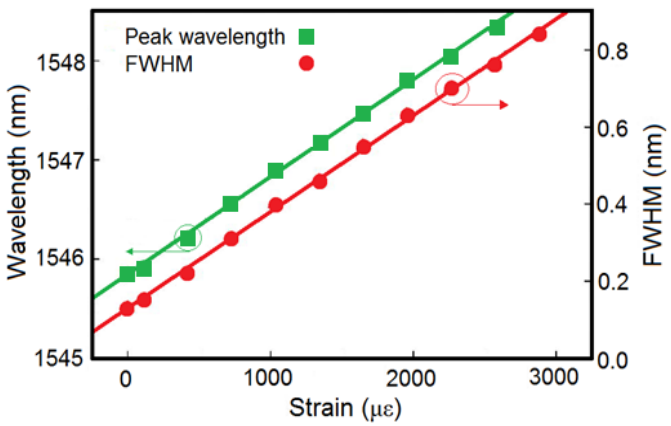

The above Figure 11 shows the response of the sensor to different values of the applied strain, which reveals the linear dependence of FWHM on the applied strain. The peak wavelength response is also linear with the applied strain [31].

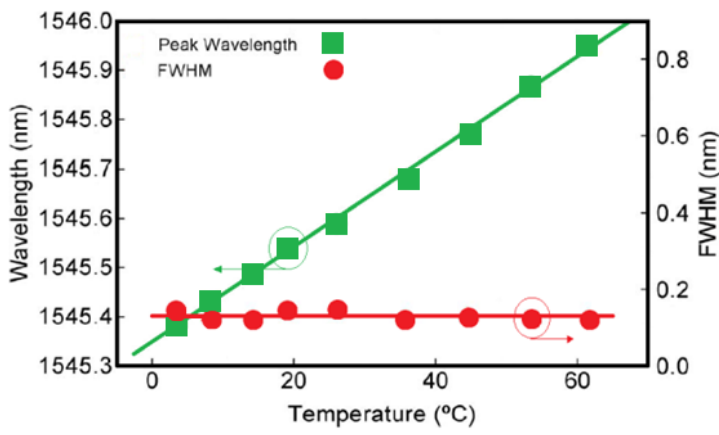

Fig. 12. Graph showing the response of the sensor to different temperature values [31]

Figure 12 shows the temperature response of the sensor head. It can be seen that as the temperature rises, the peak wavelength also increases linearly, but FWHM remains relatively at around $0.13 \mathrm{~nm}[31]$.

\section{Conclusion}

The literature examples cited in the paper clearly indicate the very accurate use of fiber-optic periodic structures in the technique of measuring non-electrical quantities such as temperature and stress. Presentation of fiber optic Bragg grids through the spectrum of metrology enabled accurate scratching of measurement intervals, presentation of features affecting the accuracy of measurement and various types of periodic structures themselves, that is grids with a constant and variable period. Taking into account the described research results taken from the literature, it is clearly visible that periodic structures work well in the role of measuring transducers of temperature and stress. The described applications thanks to the use of fiber-optic periodic structures in various configurations also enable their adaptation to other scientific fields.

\section{Reference}

[1] Albert J., Hill K.O., Malo B., Theriault S., Bilodeau F., Erickson L.E. Apodization of the spectral response of fiber Bragg gratings using a phase mask with variable diffraction efficiency. Electron. Lett. 31, 1995, 222-223.

[2] Anderson D.Z., Mizrahi V., Erdogan T., White A. E.: Production of in-fiber gratings using a diffractive optical element. Electron. Lett. 29, 1993, 566-568.

[3] Azaña J., Chen L.R., Muriel M.A., Smith P.W.E.: Experimental demonstration of real-time Fourier transformation using linearly chirped fiber Bragg gratings. Electron. Lett. 35(25), 1999, 2223-2224.

[4] Barbarin Y.: Dynamic measurements of physical quantities in extreme environment using fiber Bragg grating. 27th Optical Fiber Sensors Conference (OFS), IEEE, 2017, 1-4.

[5] Canning J.:Fibre gratings and devices for sensors and lasers. Laser \& Photonics Reviews 2(4), 2008, 275-289.

[6] Deepa S., Bhargab D.: Pico-strain-level dynamic perturbation measurement using $\Pi$ FBG sensor. arXiv preprint arXiv:1710.04206, 2017.

[7] Dziuda Ł., Krej M., Lewandowski J., Różanowski K., Skibniewski F. Światłowodowy czujnik czynności oddechowej i rytmu serca. Polski Przegląd Medycyny i Psychologii Lotniczej 3(17), 2011.

[8] Eggleton B.J., Nielsen T.N., Rogers J.A., Westbrook P.S., Strasser T.A., Hansen P. B., Dreyer K.F.: Dispersion compensation in $20 \mathrm{Gbit} / \mathrm{s}$ dynamic nonlinear lightwave systems using electrically tunable chirped fiber grating. Electron. Lett. $35,1999,832-833$.

[9] Eggleton B.J., Rogers J.A., Westbrook P.S., Strasser T.A.: Electrically tunable power efficient dispersion compensating fiber Bragg grating. IEEE Photonics Technology Letters 11(7), 1999, 854-856.

[10] Fernandez A.F., Berghmans F., Brichard B., Mégret P., Decréton M., Blonde M., Delchambre A.: Multi-component force sensor based on multiplexed fibre Bragg grating strain sensors. Meas. Sci. Technol. 12(7), 2001, 810.

[11] Garrett L.D., Gnauck A.H., Forgherieri, Scarano D.: 8 X 20 Gb/s-315 km-480 $\mathrm{km}$ WDM transmission over conventional fiber using multiple broadband fiber gratings. Tech. Digest of Conf. On Opt. Fiber Commun. OFC '98, Post-Deadline paper, PD18, 1998, 1-4.

[12] Hill P.C., Eggelton B.J.: Strain gradient chirp of fibre Bragg gratings. Electronics Letters 30(14), 1994, 1172-1174. 
[13] Hill K.O., Bilodeau F., Malo B., Kitagawa T., Thériault S., Johnson D. C. Albert J., Takiguchi K.:Chirped in-fiber Bragg gratings for compensation of optical-fiber dispersion. Opt. Lett. 19(17), 1994, 1314-1316.

[14] Hill K.O., Fujii Y., Johnson D.C., Kawasaki B.S.: Photosensitivity in optical fiber waveguides: Application to reflection filter fabrication. Appl. Phys. Lett. 32, 1978, 647-649.

[15] Hill K.O., Malo B., Bilodeau F., Johnson D.C., Albert J.: Bragg grating fabricated in monomode photosensitive optical fiber by UV exposure through a phase mask. Appl. Phys. Lett. 62, 1993, 1035-1037.

[16] Hill K.O., Meltz G.: Fiber Bragg grating technology fundamentals and overview. J. Lightwave Technol. 15, 1997, 1263-1275.

[17] Ikhlef A.: Uniform Fiber Bragg Grating modeling and simulation used matrix transfer method. International Journal of Computer Science Issues 9(1), 2012 368-374.

[18] James S.W., Dockney M.L., Tatam R.P.: Simultaneous independent temperature and strain measurement using in-fibre Bragg grating sensors. Electronics Letter 32(12), 1996, 1133-1134.

[19] Kalli K., Simpson G., Dobb H., Komodromos M., Webb D., Bennion I. Annealing and temperature coefficient study of type IA fibre Bragg gratings inscribed under strain and no strain-implications to optical fibre component reliability. Proc. SPIE 6193, 2006.

[20] Kashyap R.: Fiber Bragg Gratings. New York, Academic, 1999

[21] Kisała P., Klimek J., Skorupski K.: W pełni optyczny przełącznik wykorzystujący jednorodne światłowodowe siatki Bragga. Przegląd Elektrotechniczny 91(11), 2015, 266-270.

[22] Kisała P., Cieszzczyk S.: Method of simultaneous measurement of two direction force and temperature using fbg sensor head. Appl. Opt. 54, 2015, 2677-2687.

[23] Kisała P.: Generation of a zone chirp in uniform Bragg grating as a way of obtaining double functionality of a sensor. Metrology and Measurement Systems 4, 2012, 727-738

[24] Kisała P.: Method of simultaneous measurement of bending forces and temperature using Bragg gratings. Proc. SPIE 9506, Optical Sensors, 2015.

[25] Kisała P.: Optoelectronic sensor for simultaneous and independent temperature and elongation measurement using Bragg gratings. Przegląd Elektrotechniczny 11a, 2012, 343-346.

[26] Kisała P.: Periodyczne struktury światłowodowe w optoelektronicznych czujnikach do pomiaru wybranych wielkości nieelektrycznych. Politechnika Lubelska, 2012.

[27] Laming R.I., Ibsen M., Durkin M., Cole M.J., Zervas M.N., Ennser K.E., Gusmeroli V.: Dispersion compensation gratings. Bragg Gratings, Photosensivity, and Poling in Glass Fibers and Waveguides, Applications an Fundamentals. OSA Technical Digest Series (Optical Society of America, Washington, DC) 17, Paper BTuA7, 1997, 271-273

[28] Lazaro J.M., Quintela A., Tarnowski K., Wojcik J., Urbanczyk W., LopezHiguera J.M.: Experimental characterization of the spectral effective index dependence of index-guided photonic crystal fibers. Meas. Sci. Technol. 21 Paper 055111, 2010.

[29] Li Y., Yang M., Wang D.N., Lu J., Sun T., Grattan, K.T.: Fiber Bragg grating with enhanced thermal stability by residual stress relaxation. Optics express 17(22), 2009, 19785-19790.

[30] Liao C., Li Y., Wan, D.N., Sun T., Grattan K.T.V.: Morphology and Therma Stability of Fiber Bragg Gratings for Sensor Applications Written in $\mathrm{H}_{2}$-Free and $\mathrm{H}_{2}$-Loaded Fibers by Femtosecond Laser. IEEE Sensors Journal 10(11), $2010,1675-1681$

[31] Lima H.F., Antunes P.F., de Lemos Pinto J., Nogueira R.N.: Simultaneous measurement of strain and temperature with a single fiber Bragg grating written in a tapered optical fiber. IEEE Sensors Journal 10(2), 2010, 269-273.

[32] Liu Y., Williams J.A.R., Zhang L., Bennion, I.: Abnormal spectral evolution of fiber Bragg gratings in hydrogenated fibers. Optics letters 27(8), 2002, 586-588.

[33] Loh W.H., Laming R.I., Robinson N., Cavaciuti A., Vaninetti, Anderson C.J., Zervas M.N., Cole M.J.: Dispersion compensation over distances in excess of $500 \mathrm{~km}$ for $10 \mathrm{~Gb} / \mathrm{s}$ systems using chirped fibre gratings. IEEE Photon. Technol. Lett. 8, 1996, 944

[34] Maheshwari M., Tjin S.C., Yang Y., Asundi A.: Wavelength-shifted chirped FBGs for temperature compensated strain measurement. Sensors and Actuators A: Physical. 2017.

[35] Majumder M., Gangopadhyay T.K., Chakraborty A.K., Dasgupta K. Bhattacharya D.K.: Fiber Bragg gratings in structural health monitoring-prezen status and applications. Sensors and Actuators 147, 2008, 150-164.
[36] Malo B., Hill K.O., Bilodeau, F., Johnson D.C., Albert J.: Point-by-poin fabrication of micro-Bragg gratings in photosensitive fiber using single excime pulse refractive-index modification techniques. Electron. Lett. 29, 1993, 1668 1669

[37] Malo B., Theriault S., Johnson D.C., Bilodeau F., Albert J., Hill K.O.: Apodised in-fiber Bragg grating reflectors photoimprinted using a phase mask. Electron. Lett. 31, 1995, 223-224.

[38] Martinez A., Khrushchev I.Y., Bennion I.: Thermal properties of fibre Bragg gratings inscribed point-by-point by infrared femtosecond laser. Electron. Lett. 41, 2005, 176-178.

[39] Meltz G., Morey W.W., Glenn W.H.: Formation of Bragg gratings in optical fibers by a transverse holographic method. Opt. Lett. 14, 1989, 823-825.

[40] Ouellette F., Krug P.A., Stephens T., Dhosi G., Eggleton B.J.: Dispersion compensation using chirped sampled fibre Bragg gratings. Electronics Lett. 31 1995, 899-901.

[41] Prakash O., Kumar J., Mahakud R., Agrawal S.K, Dixit S.K., Nakhe S.V.: Enhanced Temperature $\left(\sim 800^{\circ} \mathrm{C}\right)$ Stability of Type-IIa FBG Written by $255 \mathrm{~nm}$ Beam. IEEE Photonics Technology Letters 26(1), 2014, 93-95.

[42] Putnam M.A., Williams G.M., Friebele E.J.: Fabrication of tapered, straingradient chirped fibre Bragg gratings. Electronics Letters 31.4, 1995, 309-310.

[43] Shi Ch.X.: Optical Bistability in Reflective Fiber Gratings. IEEE Journal of Quantum Electronics 31, 1995, 2037-2043.

[44] Takubo Y., Yamashita S.: High-speed dispersion-tuned wavelength-swept fiber laser using a reflective SOA and a chirped FBG. Optics express 21(4), 2013, 5130-5139.

[45] Tanaka N., Okabe Y., Takeda N.: Temperature-compensated strain measurement using fiber Bragg grating sensors embedded in composite laminates. Smart materials and structures 12(6), 2003, 940 .

[46] Williams R.J., Voigtländerv C., Marshall G.D., Tünnermann A., Nolte S., Steel M.J., Withford M.J.: Pointby-point inscription of apodized fiber Bragg gratings. Opt. Lett. 36(15), 2011, 2988-2990.

[47] Yoffe G.W., Krug P.A., Ouellette F., Thorncraft D.A.: Passive temperaturecompensating package for optical fiber gratings. Applied Optics 34(30), 1995 6859-6861.

[48] Zhu HH., Yin JH., Zhang L., Jin W., Dong JH.: Monitoring internal displacements of a model dam using FBG sensing bars. Advances in Structural Engineering 13(2), 2010, 249-262.

\section{M.Sc. Tomasz Zieliński \\ e-mail: tomasz.zielinski.1992@gmail.com}

Graduated from the Faculty of Electrical Engineering at Lublin University of Technology. Received his Master of Science degree in 2016. Title of Thesis: The analysis of sensory platform for use in the Internet of Things. Areas of interest: IoT, mobile system in mechatronics, mobile system, fiber Bragg grating.

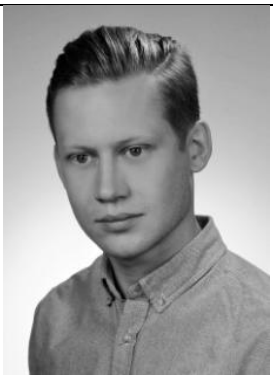

\section{D.Sc, Ph.D. Piotr Kisala}

e-mail: p.kisala@pollub.pl

Piotr Kisała is currently a professor in the Department of Institute of Electronics and Information Technology of Lublin University of Technology (LUT), Lublin, Poland. In 1997, he received a diploma in Informatic and Computer Networks from the Maria CurieSkłodowska University, Poland. He received the Ph.D. degree in 2009 and habilitation degree in 2013 from LUT. He is currently head of Optoelectronic \& ICT Department at LUT. His research interests include optical sensors projects, fabrication and testing as well as designing and developing of unconventional FBG sensors. $\mathrm{He}$ has authored over 70 journal publication and conference contributions and 2 patents. 